\title{
Long-term cardiopulmonary function after thoracic sympathectomy: Comparison between the conventional and simplified techniques
}

\author{
Miguel Angel Ponce González, MD, ${ }^{\text {a,c }}$ Gabriel Juliá Serdá, MD, ${ }^{a}$ Pedro Rodriguez Suarez, MD, ${ }^{\mathrm{b}}$ \\ Gregorio Perez-Peñate, MD, ${ }^{\mathrm{a}}$ Jorge Freixinet Gilart, MD, ${ }^{\mathrm{b}}$ and Pedro Cabrera Navarro, $\mathrm{MD}^{\mathrm{a}}$
}

Objective: We sought to compare the long-term effects of conventional and simplified thoracic sympathectomy on cardiopulmonary function.

\begin{abstract}
Methods: We performed a prospective and randomized study of 32 patients with diagnoses of primary hyperhidrosis who were candidates for either conventional or simplified thoracic sympathectomy. Patients were randomized according to the type of procedure: conventional thoracic sympathectomy (18 patients) and simplified thoracic sympathectomy (14 patients). Before surgical intervention, forced spirometry, body plethysmography, measurement of the diffusing capacity of the lung for carbon monoxide (DLCO), and exercise tests were carried out in all patients. These evaluations were performed again 1 year after the procedure to assess the long-term effects of sympathectomy.

Results: Lung function tests revealed a significant decrease in forced expiratory volume in 1 second $\left(\mathrm{FEV}_{1}\right)$ and forced expiratory flow between $25 \%$ and $75 \%$ of vital capacity $\left(\mathrm{FEF}_{25 \%-75 \%}\right)$ in both groups $(\mathrm{FEV}$ of $-6.3 \%$ and $\mathrm{FEF}_{25 \%-75 \%}$ of $-9.1 \%$ in the conventional thoracic sympathectomy group and $\mathrm{FEV}_{1}$ of $-3.5 \%$ and $\mathrm{FEF}_{25 \%-75 \%}$ of $-12.3 \%$ in the simplified thoracic sympathectomy group). Deco and heart rate at rest and maximal values after exercise were also significantly reduced in both groups (DLCO of $-4.2 \%$, DLCo corrected by alveolar volume of $-6.1 \%$, resting heart rate of -11.8 beats $/ \mathrm{min}$, and maximal heart rate of -9.5 beats $/ \mathrm{min}$ in the conventional thoracic sympathectomy group and DLCO of $-3.9 \%$, DLCO corrected by alveolar volume of $-5.2 \%$, resting heart rate of -10.7 beats/min, and maximal heart rate of -17.6 beats/min in the simplified thoracic sympathectomy group). Airway resistance increased significantly in the group of patients undergoing conventional thoracic sympathectomy $(+13 \%)$. Despite all these changes, the patients remained asymptomatic. No significant differences were found between the conventional and simplified thoracic sympathectomy groups.
\end{abstract}

Conclusions: Simplified and conventional thoracic sympathectomy resulted in a long-term reduction in FEV , $_{1}$

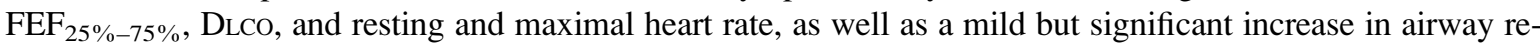
sistance in the conventional thoracic sympathectomy group, without any clinical consequence to the patient. These changes were unrelated to the level of transection of the thoracic sympathetic chain. (J Thorac Cardiovasc Surg 2010;139:405-10)

Primary essential hyperhidrosis is a condition characterized by excessive sweating. It affects primarily the hands (palmar hyperhidrosis) but can extend to the feet (plantar hyperhidrosis) and axillae. Excessive sweating is defined as sweating that exceeds physiologic needs. ${ }^{1}$ The current most accepted treatment for hyperhidrosis is the excision of T2 and T3 sympathetic ganglia in the palmar forms, whereas an additional excision of $\mathrm{T} 4$ is recommended in axillary presentations. The technique improvements achieved during the 1990s,

\footnotetext{
From the Departments of Pulmonary Medicine ${ }^{\mathrm{a}}$ and Thoracic Surgery, ${ }^{\mathrm{b}}$ and Hospital at Home Unit, ${ }^{\mathrm{c}}$ Dr Negrín Gran Canaria University Hospital, Las Palmas de Gran Canaria, Spain.

Disclosures: None.

Received for publication Feb 4, 2009; revisions received April 5, 2009; accepted for publication May 16, 2009; available ahead of print June 29, 2009.

Address for reprints: Miguel Angel Ponce González, MD, Department of Pulmonary Medicine and Hospital at Home Unit, Dr Negrín Gran Canaria University Hospital,

C/Barranco de la Ballena s/n, 35019, Las Palmas de GC, Canary Island, Spain (E-mail: migp@arrakis.es).

0022-5223/\$36.00

Copyright (c) 2010 by The American Association for Thoracic Surgery

doi:10.1016/j.jtcvs.2009.05.011
}

leading to better outcomes and low morbidity/mortality, have promoted thoracic sympathectomy as the treatment of choice for hyperhidrosis. Compensatory hyperhidrosis is the most common secondary effect, ${ }^{2}$ and it has been suggested that it could be related to the extent of the sympathicolysis. Indeed, some authors advocate a more selective and limited procedure (only at T3 level) to minimize this undesirable effect. ${ }^{3}$

Partial cardiopulmonary sympathetic denervation is a potential consequence of the T2-T4 thoracic sympathicolysis ${ }^{4}$ because sympathetic innervation for those organs derives from the cervical and thoracic sympathetic chain. ${ }^{5}$ Very few studies addressing the role of sympathetic innervation of the human lung are currently available. The airway receives a dense cholinergic postganglionic innervation stemming from the numerous parasympathetic ganglia located on the airway wall. ${ }^{6}$ The sympathetic innervation is generally rare and even controversial. However, by using electron microscopy, some studies have demonstrated the presence of adrenergic nerves in the lower respiratory tract, although at a much lower frequency than cholinergic fibers. ${ }^{7}$ 


$$
\begin{aligned}
& \text { Abbreviations and Acronyms } \\
& \text { DeCO= diffusing capacity of the lung for } \\
& \text { carbon monoxide } \\
& \mathrm{FEF}_{25 \%-75 \%}=\text { forced expiratory flow between } \\
& 25 \% \text { and } 75 \% \text { of vital capacity } \\
& \mathrm{FEV}_{1}=\text { forced expiratory volume in } \\
& 1 \text { second } \\
& \text { FVC = forced vital capacity } \\
& \text { KCO }=\text { DLCO corrected by alveolar volume } \\
& \text { Raw = airway resistance } \\
& \text { TLC = total lung capacity } \\
& \mathrm{VE} \quad=\text { minute ventilation } \\
& \mathrm{VO}_{2} \quad=\text { oxygen uptake }
\end{aligned}
$$

Very few studies have examined the effect of upper thoracic sympathectomy on cardiopulmonary function, and they all focused on short-term and midterm effects $(<6$ months after the procedure).$^{8-11}$ Our group has published the first study on the long-term assessment of pulmonary function by means of spirometry in sympathectomized patients 1 year after the operation. The results allowed us to rule out that the observed reduction in respiratory volume and flow was caused directly by the surgical technique. ${ }^{12}$ All studies published to date have only included patients operated on with conventional sympathectomy ( 2 levels, T2 and T3). Therefore no results are available on pulmonary function after simplified sympathectomy, a technique believed to be the safest and the one with the least secondary effects because it induces less compensatory hyperhidrosis. ${ }^{3,13}$ In this study we intended both to evaluate whether reducing the extent of the transected sympathetic chain modifies the cardiorespiratory functions in the long-term and to determine whether such changes are correlated with the extent and level of the sympathectomy.

\section{MATERIALS AND METHODS \\ Patients}

The study included 32 consecutive candidates for surgical treatment for primary hyperhidrosis unresponsive to conservative management. Patients were randomly selected to undergo either conventional or simplified sympathectomy. Informed consent forms were provided to and signed by all participants. The study was reviewed by the human subjects review committee of our hospital. Patients with acute or chronic pulmonary diseases were excluded from the study. None of the patients was taking medication with cardiopulmonary effects nor was a smoker.

\section{Pulmonary Function Testing}

Forced spirometry was carried out before and 1 year after surgical intervention in all patients. The same spirometer was used throughout the study (Master Screen; Jaeger, Würzburg, Germany), and the European Respiratory Society/American Thoracic Society consensus guidelines for pulmonary function testing were followed. ${ }^{14}$ Recorded parameters were forced vital capacity $(\mathrm{FVC})$, forced expiratory volume in 1 second $\left(\mathrm{FEV}_{1}\right)$, and forced expiratory flow between $25 \%$ and $75 \%$ of vital capacity $\left(\mathrm{FEF}_{25 \%-}\right.$ $75 \%$ ). Pulmonary volumes and airway resistance (Raw) were also measured before and 1 year after the operation by using body plethysmography (Master Screen Body, Jaeger), according to the European Respiratory Society/ American Thoracic Society consensus ${ }^{15}$; the recorded parameters were total lung capacity (TLC), residual volume, inspiratory and expiratory reserve volume, and Raw. All patients had measurements of diffusing capacity of the lung for carbon monoxide (DLCO) before and 1 year after the operation. A gas analyzer (Jaeger Compact-transfer) was used to estimate the diffusing capacity. The test consisted of inhalation of a gas mixture with known concentrations of $0.3 \%$ carbon monoxide, an inert gas (10\% helium), $21 \%$ oxygen, and nitrogen, according to the American Thoracic Society consensus. ${ }^{16}$ The variables obtained were DLCo and Duco corrected by alveolar volume (KCO). Finally, on a different day, an exercise test was performed with a cycloergometer (Jaeger Oxicon Delta). In all cases an increasing-intensity, symptom-limited protocol from Jones ${ }^{17}$ was applied. The test begins with a 3-minute resting period, after which the patient starts pedaling without resistance during the next 3 minutes. The patient should maintain the same speed throughout the exercise (around 60 revolutions per minute). Then resistance is gradually increased by $20 \mathrm{~W}$ each minute until either maximal tolerance is reached or the appearance of signs or symptoms requires interruption of the exercise. The following main variables were recorded at rest and at maximal effort: heart and respiratory rate, systolic and diastolic blood pressure, hemoglobin oxygen saturation, oxygen uptake $\left(\mathrm{VO}_{2}\right)$, carbon dioxide output, minute ventilation $(\mathrm{VE})$, and continuous electrocardiographic assessment.

\section{Video-Assisted Thoracoscopic Sympathectomy}

The surgical technique was performed after achievement of general anesthesia and selective bronchial intubation with a double-lumen endotracheal tube. When a proper lung collapse was not possible, the procedure was carried out during short apneas. The patient was placed in a sitting position at $90^{\circ}$ with both arms in abduction. This position enables a good separation of the lung parenchyma and the sympathetic chain, providing satisfactory visualization. Two incisions of 11 and $5 \mathrm{~mm}$, respectively, on the medial and anterior axillary lines were made, through which the endodissector $(5 \mathrm{~mm})$ and the video endoscope $(11 \mathrm{~mm})$ were introduced. In women incisions were aligned to the submammary line so as to achieve a better aesthetic result. After a unilateral lung collapse, the paravertebral sympathetic chain was identified, and the costal arches were localized. The sympathectomy on the selected costal arches consisted of a section of the chain by means of electrocoagulation. In patients with palmar hyperhidrosis, sympathectomy was performed at the level of the third costal arch (T3) in the simplified technique and the second and third arches (T2-T3) in the conventional technique. In patients with palmar and axillary hyperhidrosis, sympathectomy was performed on the third and fourth costal arches (T3-T4) in the simplified technique and on the second and fourth arches in the conventional procedure. Once the sympathetic chain was transected, the correct denervation was verified by checking the increased skin temperature of the palms. After manual expansion of the lung, a pleural drain was placed and connected to an aspiration system until air was completely expelled from the pleural cavity. The drain was then withdrawn, and both incisions were closed. A plain chest radiograph was taken in the recovery room before patients were transferred to the inpatient unit and discharged the day after the procedure.

\section{Statistical Analysis}

The pulmonary function data are expressed as means and standard deviations. Comparisons between cardiopulmonary function results involved nonparametric tests: the Wilcoxon test for paired values and the MannWhitney $U$ test for independent values. The statistical package SPSS version 15.0 (SPSS, Inc, Chicago, Ill) was used.

\section{RESULTS}

The study population consisted of 20 female and 12 male patients with a mean age of 25.44 years (range, 14-40 
years). All patients fully recovered from hyperhidrosis, which confirmed the actual interruption of the sympathetic chain and therefore the hypothetical partial cardiopulmonary denervation. None of the patients experienced cardiorespiratory complications after the operation, except for 1 patient with transient Horner's syndrome.

Results of spirometric testing, body plethysmography, DLCO, and cardiopulmonary ergometry were within the normal ranges before the operation. To analyze the results, patients were grouped according to the type of the procedure: conventional sympathectomy (18 patients; 3 or 2 levels, T2T4 or T2-T3) and simplified sympathectomy (14 patients; 2 levels or 1 level, T3-T4 or only T3; Tables 1 and 2). Significant reductions in forced spirometric values were observed for $\mathrm{FEV}_{1}$ and $\mathrm{FEF}_{25 \%-75 \%}$ in both groups 1 year after the operation (conventional sympathectomy: $\mathrm{FEV}_{1}$ of $0.230 \mathrm{~L}$ [-5.1\%] and $\mathrm{FEF}_{25 \%-75 \%}$ of $0.340 \mathrm{~L} / \mathrm{s}[-8.3 \%$ ]; simplified sympathectomy: $\mathrm{FEV}_{1}$ of $0.130 \mathrm{~L}[-2.8 \%]$ and $\mathrm{FEF}_{25 \%-75 \%}$ of $0.540 \mathrm{~L} / \mathrm{s}[-7.4 \%])$. There were no significant differences in FVC for any group. Regarding body plethysmography, Duco measurement, and exercise testing 1 year after the procedure, patients in the conventional technique group presented with a significant increase in Raw: $0.03 \mathrm{kPa} \cdot \mathrm{s}^{-1}$. $\mathrm{L}^{-1}(+13 \%)$. A significant reduction in DLCO and Kco values was also observed (conventional sympathectomy: Deco of $0.39 \mathrm{mmol} \cdot \mathrm{min}^{-1} \cdot \mathrm{kPa}^{-1}[-4.2 \%]$ and KCO of 0.11 $\mathrm{mmol} \cdot \mathrm{min}^{-1} \cdot \mathrm{kPa}^{-1} \cdot \mathrm{L}^{-1}[-6.1 \%]$; simplified sympathectomy: DLCO of $0.35 \mathrm{mmol} \cdot \mathrm{min}^{-1} \cdot \mathrm{kPa}^{-1}[-3.9 \%]$ and KCO of $\left.0.09 \mathrm{mmol} \cdot \mathrm{min}^{-1} \cdot \mathrm{kPa}^{-1} \cdot \mathrm{L}^{-1}[-5.2 \%]\right)$. However, the values for TLC and residual volume did not change significantly, nor did Raw values change in the simplified sympathectomy group. Cardiorespiratory ergometry results exhibited a significant reduction in resting and maximal heart rate in both groups (conventional sympathectomy: resting heart rate of 11.8 beats $/ \mathrm{min}$ and maximal heart rate of 9.5 beats/min; simplified sympathectomy: resting heart rate of 10.7 beats/min and maximal heart rate of 17.6 beats/min). No differences were observed at rest or after maximal effort in $\mathrm{VO}_{2}$ or in $\mathrm{VE}$. The cardiopulmonary function tests carried out did not show any significant difference between patients submitted to conventional or simplified sympathectomy (Table 3). The stratification of patients according to the levels of denervation did not reveal further differences when comparisons were performed between the following interventions: $\mathrm{T} 2$ (T2-T4 and $\mathrm{T} 2-\mathrm{T} 3$ ) versus non-T2 (T3 and T3-T4); only 1 level (T3) versus 2 or 3 levels (T2-T3, T3-T4, or T2-T4); and T4 (T2-T4 and T3-T4) versus non-T4 (T3 and T2-T3). After 1 year of follow-up, all patients remained asymptomatic.

\section{DISCUSSION}

There are very few studies that describe the changes in pulmonary function after sympathectomy and evaluate the role of the simplified technique. Such studies have assessed
TABLE 1. Changes in pulmonary function test, body plethysmography, DLCo, and exercise test results in 18 patients with palmar or palmar and axillary hyperhidrosis 12 months after conventional sympathectomy (T2-T4 and T2-T3)

\begin{tabular}{|c|c|c|c|}
\hline Parameters & $\begin{array}{c}\text { Before the } \\
\text { operation } \\
(\text { mean } \pm \text { SD) }\end{array}$ & $\begin{array}{c}\text { Twelve months } \\
\text { after the } \\
\text { operation } \\
(\text { mean } \pm \text { SD) }\end{array}$ & $\begin{array}{c}P \\
\text { value } \\
\end{array}$ \\
\hline $\mathrm{FVC}(\mathrm{L})$ & $4.43 \pm 0.81$ & $4.30 \pm 1.11$ & NS \\
\hline FVC $(\%)$ & $105.7 \pm 12.6$ & $101.7 \pm 26.2$ & NS \\
\hline $\mathrm{FEV}_{1}(\mathrm{~L})$ & $3.65 \pm 0.89$ & $3.42 \pm 0.79$ & $<.05$ \\
\hline $\mathrm{FEV}_{1}(\%)$ & $108.3 \pm 11.9$ & $103.2 \pm 10.4$ & $<.05$ \\
\hline $\mathrm{FEF}_{25 \%-75 \%}(\mathrm{~L} / \mathrm{s})$ & $3.74 \pm 1.18$ & $3.40 \pm 1.08$ & $<.05$ \\
\hline $\mathrm{FEF}_{25 \%-75 \%}(\%)$ & $91.2 \pm 24.4$ & $82.9 \pm 22.3$ & $<.05$ \\
\hline TLC (L) & $5.86 \pm 1.21$ & $5.81 \pm 1.17$ & NS \\
\hline TLC $(\%)$ & $111.43 \pm 14$ & $110.7 \pm 12.8$ & NS \\
\hline RV (L) & $1.55 \pm 0.35$ & $1.61 \pm 0.27$ & NS \\
\hline RV $(\%)$ & $118.3 \pm 30.9$ & $119.8 \pm 27.7$ & NS \\
\hline $\operatorname{Raw}\left(\mathrm{kPa} \cdot \mathrm{s}^{-1} \cdot \mathrm{L}^{-1}\right)$ & $0.20 \pm 0.08$ & $0.23 \pm 0.05$ & $<.05$ \\
\hline Raw $(\%)$ & $81.2 \pm 36.1$ & $78.9 \pm 23.4$ & NS \\
\hline $\operatorname{DLCO}\left(\mathrm{mmol} \cdot \min ^{-1} \cdot \mathrm{kPa}^{-1}\right)$ & $9.26 \pm 2.77$ & $8.87 \pm 2.8$ & $<.05$ \\
\hline $\mathrm{KCO}\left(\mathrm{mmol} \cdot \min ^{-1} \cdot \mathrm{kPa}^{-1} \cdot \mathrm{L}^{-1}\right)$ & $1.79 \pm 0.22$ & $1.68 \pm 0.23$ & $<.05$ \\
\hline Resting VE (L/min) & $12.08 \pm 5.9$ & $11.1 \pm 4.63$ & NS \\
\hline Peak Ve (L/min) & $80.92 \pm 37.9$ & $86.1 \pm 29.6$ & NS \\
\hline Peak VE $(\%)$ & $79.7 \pm 25.1$ & $80.8 \pm 17.9$ & NS \\
\hline Resting $\mathrm{VO}_{2}(\mathrm{~mL} / \mathrm{min})$ & $376.7 \pm 241.2$ & $342.6 \pm 176.5$ & NS \\
\hline Peak $\mathrm{VO}_{2}(\mathrm{~mL} / \mathrm{min})$ & $2351.5 \pm 954.6$ & $2385.1 \pm 846.6$ & NS \\
\hline Peak $\mathrm{VO}_{2}(\%)$ & $88.8 \pm 9.7$ & $92.7 \pm 12.3$ & NS \\
\hline Resting HR (beats/min) & $84.8 \pm 12.3$ & $73 \pm 13.3$ & $<.05$ \\
\hline Peak HR (beats/min) & $172.2 \pm 17.4$ & $162.7 \pm 16.9$ & $<.05$ \\
\hline
\end{tabular}

$D L C O$, Diffusing capacity of the lung for carbon monoxide; $S D$, Standard deviation $F V C$, forced vital capacity; $N S$, not significant; $F E V_{l}$, forced expiratory volume in 1 second; $F E F_{25 \%-75 \%}$, forced expiratory flow at $25 \%$ to $75 \%$ of vital capacity; $T L C$, total lung capacity; $R V$, residual volume; Raw, airway resistance; $K C O$, DLCo corrected by alveolar volume; $V E$, minute ventilation; $V_{2}$, oxygen uptake; $H R$, heart rate.

short-term and midterm pulmonary changes $(1,3$, and 6 months) after sympathectomy. ${ }^{8-11}$ The first 2 investigations, published by Molho and colleagues ${ }^{8}$ in the 1970s and 1980s, compared sympathectomies using either supraclavicular or transaxillary thoracotomy. They observed a reduction in pulmonary volumes and flows at 3 weeks and 3 and 6 months after surgical intervention. In a previous study we assessed the long-term effects of thoracoscopic sympathectomy on pulmonary function (1 year after the operation), and we demonstrated a sustained and significant decrease in $\mathrm{FEV}_{1}$ and $\mathrm{FEF}_{25 \%-75 \% .}{ }^{12}$ These data confirmed that partial sympathetic denervation in patients with hyperhidrosis results in a disturbance of bronchomotor tone and supported the role of the sympathetic nervous system in respiratory function.

Given the controversial role of the sympathetic nervous system in cardiorespiratory function, we aimed at further characterizing it by taking advantage of various surgical sympathectomy approaches. In this case we decided to compare patients undergoing conventional versus simplified sympathectomy on the hypothesis that a more limited section of the sympathetic chain would have less negative 
TABLE 2. Changes in pulmonary function test, body plethysmography, DLCo, and exercise test results in 14 patients with palmar or palmar and axillary hyperhidrosis 12 months after simplified sympathectomy (T3-T4 and T3)

\begin{tabular}{|c|c|c|c|}
\hline Parameters & $\begin{array}{c}\text { Before the } \\
\text { operation } \\
(\text { mean } \pm \text { SD) }\end{array}$ & $\begin{array}{c}\text { Twelve months } \\
\text { after the } \\
\text { operation } \\
\text { (mean } \pm \text { SD) }\end{array}$ & $\begin{array}{c}P \\
\text { value } \\
\end{array}$ \\
\hline FVC (L) & $4.41 \pm 0.81$ & $4.31 \pm 1.1$ & NS \\
\hline FVC $(\%)$ & $104.5 \pm 8.9$ & $102.7 \pm 10.9$ & NS \\
\hline $\mathrm{FEV}_{1}(\mathrm{~L})$ & $3.64 \pm 0.88$ & $3.51 \pm 0.8$ & $<.05$ \\
\hline $\mathrm{FEV}_{1}(\%)$ & $106.5 \pm 10.6$ & $103.7 \pm 9.8$ & $<.05$ \\
\hline $\mathrm{FEF}_{25 \%-75 \%}(\mathrm{~L} / \mathrm{s})$ & $4.36 \pm 1.65$ & $3.82 \pm 1.2$ & $<.05$ \\
\hline $\mathrm{FEF}_{25 \%-75 \%}(\%)$ & $89 \pm 36.8$ & $81.6 \pm 26.1$ & $<.05$ \\
\hline TLC (L) & $5.80 \pm 1.1$ & $5.77 \pm 1.2$ & NS \\
\hline TLC $(\%)$ & $105.1 \pm 9.7$ & $103.9 \pm 9.2$ & NS \\
\hline $\mathrm{RV}(\mathrm{L})$ & $1.58 \pm 0.3$ & $1.54 \pm 0.4$ & NS \\
\hline RV $(\%)$ & $108.1 \pm 20.4$ & $104.2 \pm 24$ & NS \\
\hline $\operatorname{Raw}\left(\mathrm{kPa} \cdot \mathrm{s}^{-1} \cdot \mathrm{L}^{-1}\right)$ & $0.20 \pm 0.05$ & $0.22 \pm 0.07$ & NS \\
\hline Raw $(\%)$ & $68.3 \pm 20.8$ & $73.1 \pm 21.5$ & NS \\
\hline DLCO $\left(\mathrm{mmol} \cdot \min ^{-1} \cdot \mathrm{kPa}^{-1}\right)$ & $8.83 \pm 2.5$ & $8.48 \pm 2.5$ & $<.05$ \\
\hline $\mathrm{KCO}\left(\mathrm{mmol} \cdot \mathrm{min}^{-1} \cdot \mathrm{kPa}^{-1} \cdot \mathrm{L}^{-1}\right)$ & $1.72 \pm 0.2$ & $1.63 \pm 0.2$ & $<.05$ \\
\hline Resting VE (L/min) & $9.87 \pm 2.20$ & $11.8 \pm 4$ & NS \\
\hline Peak VE (L/min) & $85.3 \pm 23.1$ & $77.9 \pm 23.3$ & NS \\
\hline Peak VE $(\%)$ & $85.6 \pm 16$ & $78.6 \pm 13.5$ & NS \\
\hline Resting $\mathrm{Vo}_{2}(\mathrm{~mL} / \mathrm{min})$ & $309.2 \pm 79.8$ & $356.3 \pm 128.5$ & NS \\
\hline Peak $\mathrm{VO}_{2}(\mathrm{~mL} / \mathrm{min})$ & $2298.1 \pm 782.4$ & $2222.1 \pm 717.9$ & NS \\
\hline Peak $\mathrm{VO}_{2}(\%)$ & $93.5 \pm 13.8$ & $91.8 \pm 15$ & NS \\
\hline Resting HR (beats/min) & $89.7 \pm 20.1$ & $79 \pm 15$ & $<.05$ \\
\hline Peak HR (beats/min) & $179 \pm 19.6$ & $161.4 \pm 29.8$ & $<.05$ \\
\hline
\end{tabular}

DLCO, Diffusing capacity of the lung for carbon monoxide; $S D$, Standard deviation $F V C$, forced vital capacity; $N S$, not significant; $F E V_{l}$, forced expiratory volume in 1 second; $F E F_{25 \%-75 \%}$, forced expiratory flow at $25 \%$ to $75 \%$ of vital capacity; $T L C$, total lung capacity; $R V$, residual volume; Raw, airway resistance; $K c O$, DLco corrected by alveolar volume; $V E$, minute ventilation; $\mathrm{VO}_{2}$, oxygen uptake; $H R$, heart rate.

consequences on cardiorespiratory function in patients with hyperhidrosis. The results revealed a significant reduction in $\mathrm{FEV}_{1}$ and $\mathrm{FEF}_{25 \%-75 \%} 1$ year after surgical intervention in patients subjected to conventional sympathectomy (with 2or 3-level sections), as well as in patients undergoing the simplified procedure (with 1- or 2-level sections). It could be considered that the decrease in $\mathrm{FEV}_{1}$ and $\mathrm{FEF}_{25 \%-75 \%}$ is due to the passage of time. In this regard Fletcher and Peto $^{18}$ showed that the decrease in $\mathrm{FEV}_{1}$ according to age is about 25 to $30 \mathrm{~mL}$ per year, on average. However, we found that the mean change in $\mathrm{FEV}_{1}$ in the conventional sympathectomy group was $230 \mathrm{~mL}$, and that in the simplified sympathectomy group was $130 \mathrm{~mL}$. Moreover, the yearly decrease in $\mathrm{FEV}_{1}$ observed in the whole population increases with age. ${ }^{18}$ Probably in our young population a normal reduction is less than 25 to $30 \mathrm{~mL}$.

Another cause that could explain the changes in lung function is the effects of the surgical procedure on the chest wall. If this were true, we would have mainly expected a decrease in FVC or TLC. In our study neither of these parameters was significantly reduced, suggesting that the decrease
TABLE 3. Comparison of the changes in pulmonary function test, body plethysmography, DLco, and exercise test results 12 months after surgical intervention in patients undergoing conventional $(n=$ 18) or simplified $(n=14)$ sympathectomy

\begin{tabular}{|c|c|c|c|}
\hline & $\begin{array}{l}\text { Conventional } \\
(\text { mean } \pm \text { SD })\end{array}$ & $\begin{array}{c}\text { Simplified } \\
(\text { mean } \pm \text { SD })\end{array}$ & $\begin{array}{c}P \\
\text { value }\end{array}$ \\
\hline FVC (L) & $4.30 \pm 1.11$ & $4.31 \pm 1.1$ & NS \\
\hline FVC $(\%)$ & $101.7 \pm 26.2$ & $102.7 \pm 10.9$ & NS \\
\hline $\mathrm{FEV}_{1}(\mathrm{~L})$ & $3.42 \pm 0.79$ & $3.51 \pm 0.8$ & NS \\
\hline $\mathrm{FEV}_{1}(\%)$ & $103.2 \pm 10.4$ & $103.7 \pm 9.8$ & NS \\
\hline $\mathrm{FEF}_{25 \%-75 \%}(\mathrm{~L} / \mathrm{s})$ & $3.40 \pm 1.08$ & $3.82 \pm 1.2$ & NS \\
\hline $\mathrm{FEF}_{25 \%-75 \%}(\%)$ & $82.9 \pm 22.3$ & $81.6 \pm 26.1$ & NS \\
\hline TLC (L) & $5.81 \pm 1.17$ & $5.77 \pm 1.2$ & NS \\
\hline TLC $(\%)$ & $110.7 \pm 12.8$ & $103.9 \pm 9.2$ & NS \\
\hline $\mathrm{RV}(\mathrm{L})$ & $1.61 \pm 0.27$ & $1.54 \pm 0.4$ & NS \\
\hline $\mathrm{RV}(\%)$ & $119.8 \pm 27.7$ & $104.2 \pm 24$ & NS \\
\hline $\operatorname{Raw}\left(\mathrm{kPa} \cdot \mathrm{s}^{-1} \cdot \mathrm{L}^{-1}\right)$ & $0.23 \pm 0.05$ & $0.22 \pm 0.07$ & NS \\
\hline $\operatorname{Raw}(\%)$ & $78.9 \pm 23.4$ & $73.1 \pm 21.5$ & NS \\
\hline $\operatorname{DLCO}\left(\mathrm{mmol} \cdot \min ^{-1} \cdot \mathrm{kPa}^{-1}\right)$ & $8.87 \pm 2.8$ & $8.48 \pm 2.5$ & NS \\
\hline $\mathrm{KCO}\left(\mathrm{mmol} \cdot \min ^{-1} \cdot \mathrm{kPa}^{-1} \cdot \mathrm{L}^{-1}\right)$ & $1.68 \pm 0.23$ & $1.63 \pm 0.2$ & NS \\
\hline Resting VE (L/min) & $11.1 \pm 4.63$ & $11.8 \pm 4$ & NS \\
\hline Peak VE (L/min) & $86.1 \pm 29.6$ & $77.9 \pm 23.3$ & NS \\
\hline Peak VE $(\%)$ & $80.8 \pm 17.9$ & $78.6 \pm 13.5$ & NS \\
\hline Resting $\mathrm{VO}_{2}(\mathrm{~mL} / \mathrm{min})$ & $342.6 \pm 176.5$ & $356.3 \pm 128.5$ & NS \\
\hline Peak $\mathrm{VO}_{2}(\mathrm{~mL} / \mathrm{min})$ & $2385.1 \pm 846.6$ & $2222.1 \pm 717.9$ & NS \\
\hline Peak $\mathrm{Vo}_{2}(\%)$ & $92.7 \pm 12.3$ & $91.8 \pm 15$ & NS \\
\hline Resting HR (beats/min) & $73 \pm 13.3$ & $79 \pm 15$ & NS \\
\hline Peak HR (beats/min) & $162.7 \pm 16.9$ & $161.4 \pm 29.8$ & NS \\
\hline
\end{tabular}

DLCO, Diffusing capacity of the lung for carbon monoxide; $S D$, Standard deviation $F V C$, forced vital capacity; $N S$, not significant; $F E V_{l}$, forced expiratory volume in 1 second; $F E F_{25 \%-75 \%}$, forced expiratory flow at $25 \%$ to $75 \%$ of vital capacity; $T L C$, total lung capacity; $R V$, residual volume; Raw, airway resistance; $K C O$, DLco corrected by alveolar volume; $V E$, minute ventilation; $V_{2}$, oxygen uptake; $H R$, heart rate.

in $\mathrm{FEV}_{1}$ and $\mathrm{FEF}_{25 \%-75 \%}$ reflects an alteration in bronchomotor tone. Furrer and associates ${ }^{19}$ studied pulmonary function after thoracic surgery (thoracotomy and thoracoscopy). They showed a reduction in FVC and $\mathrm{FEV}_{1}$ that returned to normal 4 months after the procedure. In our study the measurement of lung function was carried out a year after the operation, making it unlikely that such a decrease could be attributed to the technique.

This study has also included the measurement of lung volume, Raw, DLCO, and cardiocirculatory response to exercise. We performed these tests 1 year after the surgical procedure, as in our first study. No significant differences were found in lung volume; however, the significant increase in Raw in the conventional method group along with a decrease in $\mathrm{FEV}_{1}$ and $\mathrm{FEF}_{25 \%-75 \%}$ suggested a role of the sympathetic nervous system on bronchomotor tone. We did not find any differences in Raw in the group of patients treated with the simplified method. However, the small size of the sample in our study (14 patients) could account for this observation.

The influence of the autonomous nervous system on DLCO is poorly understood. Noppen and Vincken ${ }^{20}$ studied the 
effects of conventional T2-T3 thoracic sympathectomy only 6 weeks after surgical intervention and found a significant reduction in pulmonary DLCO (DLCO, $-6.7 \%$; KCO, $-4.2 \%$ ). Our results confirmed that DLCo significantly decreases in patients undergoing either conventional or simplified sympathectomy and that this decrease persists 1 year after the procedure. It appears unlikely that this significant reduction in pulmonary diffusion capacity is due to a decrease in TLC because the latter was virtually negligible $(<0.1 \mathrm{~L})$ in both groups. These findings indicate that the sympathetic nervous system not only plays a role in the regulation of bronchomotor tone but also in the long-term diffusion capacity of the lung. The mechanisms underlying these changes could be multiple. Noppen and Vincken ${ }^{20}$ proposed an alteration in blood flow (caused by perturbed pulmonary vasoconstriction) that would enhance lung capillary permeability, leading to an increase in total interstitial fluid and to changes in the composition and thickness of the alveolar-capillary membrane. Another potential explanation is that the decrease in vascular tone generated by the partial sympathetic denervation of the lung, along with the increase in bronchomotor tone, leads to the reduction in DLCO.

Regarding the cardiorespiratory ergometry, Noppen and coworkers ${ }^{4}$ also studied patients subjected to thoracic sympathectomy only 1 month after surgical intervention. They demonstrated that the procedure induces significant modifications of cardiac function as measured by heart rate both at rest and in response to exercise without detecting changes in $\mathrm{VO}_{2}$ uptake. However, a reduction in $\mathrm{VO}_{2}$ after surgical intervention was found by Papa and colleagues ${ }^{21}$ in patients subjected to sympathectomy by means of thoracotomy; this decrease in oxygen intake could be explained by the thoracotomy itself. In another recent study Vigil and associates ${ }^{11}$ observed in 20 patients 3 months after surgical intervention that only maximal heart rate after exercise was affected, with heart rate at rest unchanged. Our results showed significant differences in both values in patients undergoing either conventional or simplified sympathectomy. In consequence, there seems to be evidence that sympathectomy entails not only partial denervation of the lung but also of the heart. Indeed, upper thoracic sympathectomy has been investigated in the treatment of angina, ventricular tachycardia, and arrhythmias associated with the long QT syndrome. ${ }^{22}$ Several studies have also demonstrated decreased plasma levels of noradrenaline in patients undergoing sympathectomy. ${ }^{23} \mathrm{Be}-$ cause no differences were found in our study between approaches including $\mathrm{T} 2$ and the others levels, we suggest that the removal of any of these levels (T2, T3, or T4) will have a similar effect on heart rate.

We did not detect any difference in cardiopulmonary function between patients undergoing conventional or simplified sympathectomy. Therefore the reduction in the amount of sympathetic nervous fibers sectioned when a simplified sympathectomy is carried out does not seem to impli- cate a less significant decrease in pulmonary or cardiac function. The cervicothoracic branches, which have the capacity to innervate the bronchial tree and stay put after the simplified sympathectomy, could account for this observation. ${ }^{5}$ The likely existence of the so-called nerves of Kuntz, whose sympathetic connections avoid the second and third ganglia, thus directly connecting to the brachial plexus and perhaps conveying nervous fascicles to the bronchial tree, should be mentioned. ${ }^{24}$ In any case it is worth emphasizing a trend that points to a lesser reduction in lung volumes and flows in patients undergoing simplified sympathectomy who were hypothetically subjected to a less important sympathetic denervation. A larger sample size will be necessary to confirm this tendency.

This is the first study assessing the long-term effects of sympathectomy on cardiopulmonary function and comparing the conventional and simplified techniques. The results suggest that sympathectomy induces long-term modifications on cardiopulmonary function, revealing the effect of the sympathetic nervous system on this apparatus, at least in patients with primary hyperhidrosis. It has been demonstrated that both surgical techniques are safe in the longterm because we observed minimal and clinically irrelevant reductions in $\mathrm{FEV}_{1}, \mathrm{FEF}_{25 \%-75 \%}$, Raw, DLCO, and at-rest and maximal heart rate. Furthermore, the fact that a decrease in peak $\mathrm{VO}_{2}$ was not found might indicate that the observed changes do not affect performance during maximal exercise. These modifications are independent of the extent and level of the transection of the sympathetic chain because they appear in patients undergoing both conventional and simplified sympathectomy.

\section{References}

1. Moran KT, Brady MP. Surgical management of primary hyperhidrosis. Br J Surg. 1991;78:279-83.

2. Neelan D, Shannon H, Mary W, Lynne H, Syma P, Meyer DM. Thoracoscopic sympathectomy for hyperhidrosis: indications and results. Ann Thorac Surg. 2004;77:410-4.

3. Riet M, Smet AA, Kuiken H, Kazemier G, Bonjer HJ. Prevention of compensatory hyperhidrosis after thoracoscopic sympathectomy for hyperhidrosis. Surg Endosc. 2001;15:1159-62.

4. Noppen M, Herregodts P, Dendale P, D'Haens J, Vincken W. Cardiopulmonary exercise testing following bilateral thoracoscopic symphaticolysis in patients with essential hyperhidrosis. Thorax. 1995;50:1097-100.

5. Lazorthes G. Cadena simpática laterovertebral. In: Lazorthes G, ed. Descripción, sistematización y exploración del sistema nervioso autónomo. Capítulo XXIV. 1st ed. Barcelona: Toray-Mason; 1976. p. 325-57.

6. Barnes PJ. Airway inflammation and autonomic control. Eur J Respir Dis. 1986; 147:80-7

7. Laitinen A, Partanen M, Hervonen A. Electron microscopy study on the innervation of the human lower respiratory tract: evidence of adrenergic nerves. Eur J Re spir Dis. 1985;67:208-15.

8. Molho M, Shemesh E, Gordon D, Adar R. Pulmonary functional abnormalities after upper dorsal sympathectomy. Chest. 1980;77:651-5.

9. Tseng MY, Tseng JH. Thoracoscopic sympathectomy for palmar hyperhidrosis: effects on pulmonary function. J Clin Neurosci. 2001;8:539-41.

10. Noppen M, Vincken W. Thoracoscopic sympathicolysis for essential hyperhidrosis: effects on pulmonary function. Eur Respir J. 1996;9:1660-4.

11. Vigil L, Calaf N, Codina E, Fibla JJ, Gomez G, Casan P. Video-assisted sympathectomy for essential hyperhidrosis. Chest. 2005;128:2702-5. 
12. Ponce MA, Juliá G, Santana N, Rodríguez P, Pérez-Peñate G, Freixinet J, et al. Long-term pulmonary function following thoracic sympathectomy. JThorac Cardiovasc Surg. 2004;129:1378-81.

13. De Campos JR, Kauffman P, Werebe Ede C, Andrade Filho LO, Kusniek S. Quality of life, before and after thoracic sympathectomy. Report of 378 operated patients. Ann Thorac Surg. 2003;76:886-91.

14. Miller MR, Hankinson J, Brusasco V, Burgos F, Cadaburi R, Coates A, et al. Standardization of spirometry. Eur Respir J. 2005;26:319-38.

15. Clausen JL, Coates Al, Quanjer PH. Measurement of lung volume in humans: review and recommendations from an ATS/ERS workshop. Eur Respir J. 1997;10:1205-6.

16. American Thoracic Society. Single-breath carbon monoxide diffusing capacity (transfer factor). Am J Respir Crit Care Med. 1995;152:2185-98.

17. Jones NL. Clinical exercise testing. 4th ed. Philadelphia: Saunders Company; 1997. p. 1-259.

18. Fletcher C, Peto R. The natural history of chronic airflow obstruction. BMJ. 1977; $1: 1645-8$.
19. Furrer M, Rechsteiner R, Eigenmann V, Signer C, Althaus U, Ris H. Thoracotomy and thoracoscopy: postoperative pulmonary function, pain and chest wall complaints. Eur J Cardiothorac Surg. 1997;12:82-7.

20. Noppen M, Vincken W. Partial pulmonary sympathetic denervation by thoracoscopic D2-3 sympathicolysis for essential hyperhidrosis: effect on the pulmonary diffusion capacity. Respir Med. 1997;91:537-45.

21. Papa MZ, Schneiderman J, Tucker E, Bass A, Drori Y, Adar R. Cardiovascular changes after bilateral upper dorsal sympathectomy. Ann Surg. 1986;204: 715-8.

22. Kadowaki MH, Levitt JM. Sympathectomy in the treatment of angina and arrhythmias. Ann Thorac Surg. 1986;41:572-8.

23. Noppen M, Sevens C. Plasma catecholamine concentrations in essential hyperhidrosis and effects of thoracoscopic D2-3 sympathicolisis. Eur J Clin Invest. 1997; 27:202-5.

24. Ramsaroop L, Singh B, Moodley J. A thoracoscopic view of the nerve of Kuntz. Surg Endosc. 2003; 17:1498. 